\title{
Molecularium Explores the World of Materials
}

"If only one idea had to be passed on to the next generation, it is the concept of atoms and molecules, and that everything is made of them," wrote physicist Richard Feynman in his famous Lectures on Physics in 1970. Indeed, even today, one cannot think of a more powerful message to pass on to our children. The world of atoms and molecules is intricately integrated into the thinking of every materials scientist and engineer. Be it a new car bumper, the next generation of computer chips, or a discovery of the latest drug molecule- the understanding of molecular structure and how it influences the behavior and properties of molecules and materials is the fundamental goal of much of our current materials research effort.

As we enter the 21st century, a truly grand challenge facing our materials research community is to educate and excite the general public about our scientific world, and help create a scientifically literate society. A more informed public will naturally be better prepared to understand complex issues ranging from global warming and energy conservation to genetically modified foods and nutrition.

Fascinated by the world of atoms, molecules, and materials, we decided to take up this grand challenge and contribute in our own way by reaching out to the next generation early. The concept of the Molecularium $^{\mathrm{TM}}$ was thus conceived and has gradually taken shape over the last two years. Like the words "aquarium" or "planetarium," Molecularium conjures up images-in this case, of the fascinating world of molecules, where we meet characters based on atoms, take rides through materials they constitute, and with them learn more about the world around us. That is precisely our vision.

To begin, we have developed our first show-"Molecularium: Riding Snowflakes" - which uses a dome theater setting like a planetarium, but instead of taking children on a journey to distant planets, the show immerses them in the nanoscale world. The theater can be either a permanent installment, as in existing planetariums, or a portable, inflatable dome that can be easily transported to schools and other venues. For the show to be really effective, we realized that it had to be not only scientifically accurate, but also entertaining, engaging, and fun. We have now been able to make significant advances in this direction, thanks to a supplemental grant in 2003 from the U.S. National Science Foundation to our Nanoscale Science and Engineering Center for Directed Assembly of Nanostructures.

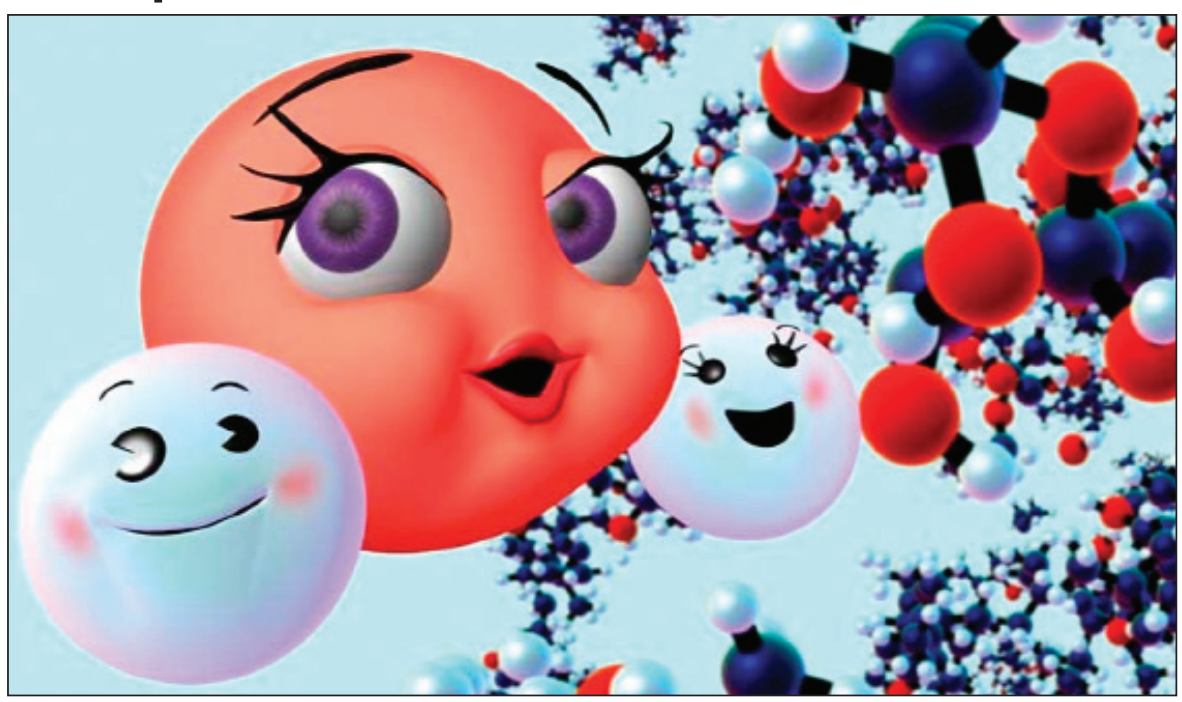

Figure 1. In the Molecularium show, children meet Oxy, an oxygen atom (red), who shows Hydra and Hydro, two hydrogen atoms, the world of materials.

In the first show, debuting in February 2005, the children meet Oxy (see Figure 1), an oxygen atom with the voice of an eightyear-old girl, who takes the younger Hydra and Hydro, two hydrogen atoms, on a test drive of the ship of the Molecularium show. The ship is amazing - it can shrink to molecular sizes and move as fast as the speed of light. Although the concept is perhaps similar to that of the movie Fantastic Voyage (1966) or the Magic School Bus on PBS in the 1990s, our merging of advanced scientific computation with state-of-the-art digital animation technology in the Molecularium show takes those previous ideas to a new level.

With the help of the ship's computer, Oxy, Hydra, and Hydro manage to navigate the ship through the clouds, where they travel into a snowflake, watch it melt, and feel and observe the wind blowing past them. Musical segments emphasize the main message that everything is made of atoms and molecules. Children also learn about the three states of matter (solid, liquid, and gas) and take a ride along a polymer molecule. Carbone (a carbon atom), who meets our trio on their brief journey through space, takes them to his favorite place, the Earth-a place teeming with life-where he retires to join a polypeptide chain and be part of life itself!

The merging of advanced scientific computation in materials with current animation technology represents one of the innovative aspects of our show. For many of the animations, such as the melting of ice, or protein dynamics in a plant leaf, we generated detailed atomic trajectories by solving Newton's equations of motion (as in molecular dynamics simulations) on clusters of computers and then exported the coordinates to the animation software (MAYA). Thanks to the experience and creative vision of director V. Owen Bush and his team of expert animators at Tektraxadex, and to the enormous effort

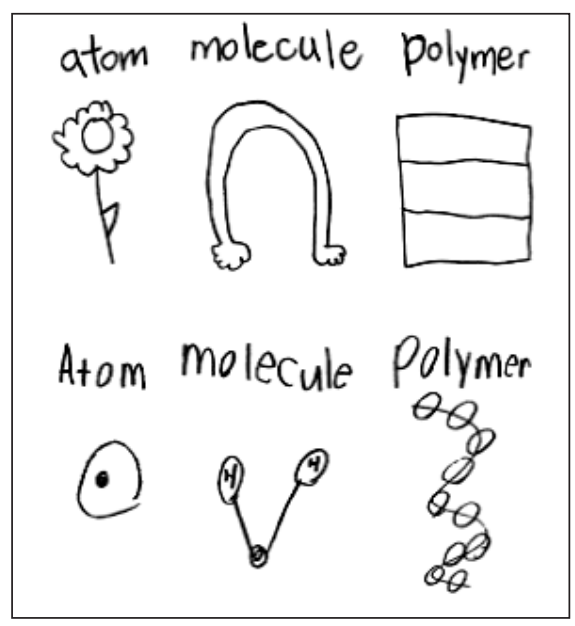

Figure 2. Educational activities are designed to reemphasize key concepts through fun group activities.

Assessment of a pilot version of the Molecularium show tells us that children do learn, as demonstrated by their versions of an atom, a molecule, and a polymer before (top panel) and after (bottom panel) watching the pilot show. 
put in by the Rensselaer Sim Team (comprising mostly graduate students in Shekhar Garde's laboratory), the result is spectacular! The visual impact is enhanced by music, lyrics, sound effects, and dialogue, which we believe will keep not only children but also their parents fully engaged throughout the show.

The potential of programs such as the Molecularium is enormous. We imagine children walking through a future Molecularium exhibit, where they will wear special glasses, immerse themselves in the virtual atomic world, play with atoms and molecules, and learn about various materials and life's building blocks.

In all of these efforts, perhaps the most important contribution comes from the children themselves, those from local schools who have provided much motivation and significant useful feedback (see Figure 2). Our own children, who have seen "in progress" versions of the Molecu- larium show, told us what is cool and what is not. It appears that the complex molecular concepts are reaching them: Linda Schadler's daughter, just four years old, recently informed her mom that her orange juice is made of molecules. And we will be making an Oxy costume for Dick Siegel's four-year-old granddaughter, who wants it for next Halloween.

To succeed, an effort of this magnitude requires the help and support of a large number of people from a variety of backgrounds. Our extended team includes 75 people, including Rensselaer faculty and students from the Departments of Materials Science and Engineering, Chemical and Biological Engineering, and Computer Science; animators and other professionals at Tektraxadex; computer system administrators; staff of the Children's Museum of Science and Technology in Troy, N.Y.; and local high school teachers. Our team has developed pre- and post-show group activities that emphasize the concepts learned during the show. We have also made sure that our use of scientific terminology is consistent with the New York state $\mathrm{K}-3$ curriculum; field trips to watch the Molecularium show at the Junior Museum can thus help complement what students are learning in class.

For more information, see Web site www.molecularium.com.

SHEKHAR GARDE LINDA S. SCHADLER RICHARD W. SIEGEL

Shekhar Garde, Linda S. Schadler, and Richard W. Siegel are involved with the Nanoscale Science and Engineering Center for Directed Assembly of Nanostructures at Rensselaer Polytechnic Institute. This work was supported by the Nanoscale Science and Engineering Initiative of the U.S. National Science Foundation under NSF award DMR0117792. For more information, see Web site www.rpi.edu/dept/nsec.

\section{Curriculum Mाब्ज $=1$ rossioads

UPCOMING MRS MEETINGS
AND WORKSHOPS
2005 MRS SPRING MEETING
March 28-April 1
Exhibit: March 29-31
San Francisco, CA
woRKSHOP-
The Physics and Chemistry of Switching in
Condensed Matter
April 1-2, 2005
San Francisco, CA
woRKSHOP-
Organic Microelectronics Workshop
July 10-13, 2005
Newport, RI
2005 MRS FALL MEETING
November 28-December 2
Exhibit: November 29-December 1
Boston, MA
For more information on these and other meeting/workshop
activities from the Materials Research Society visit
www.mrs.org/meetings.

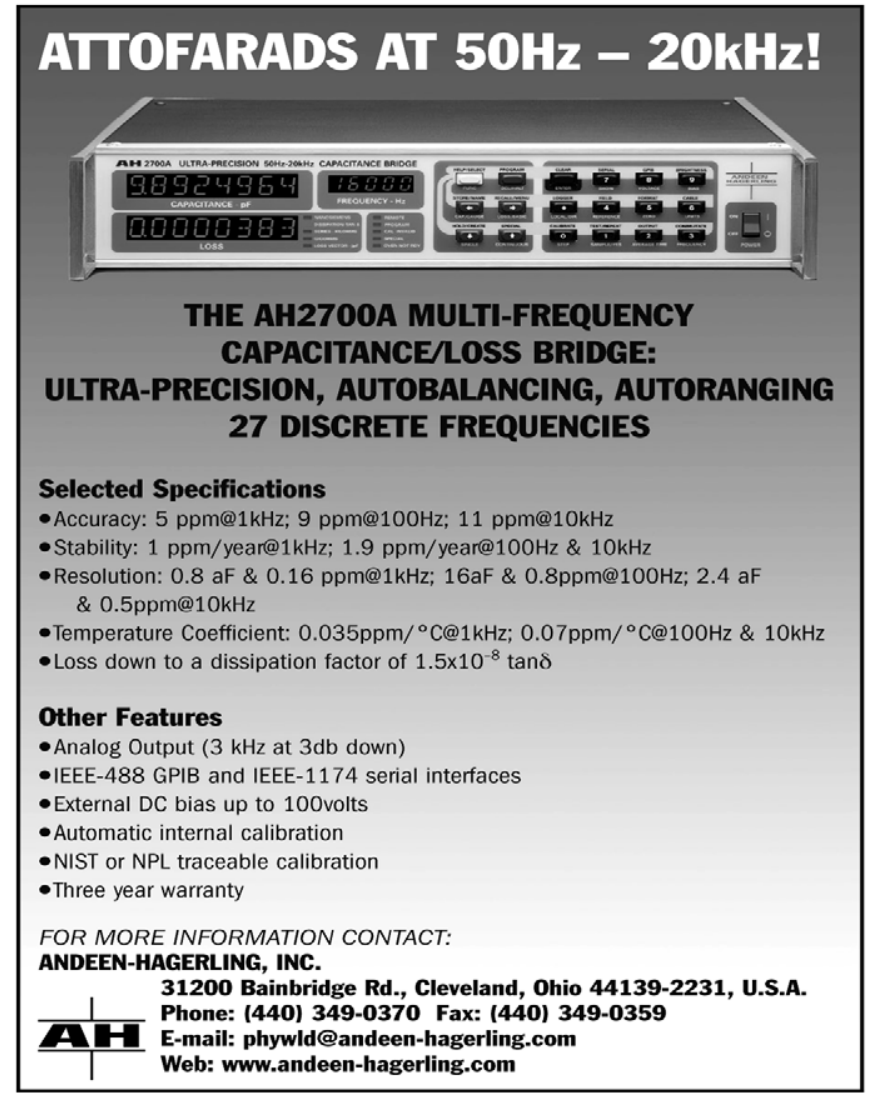

For more information, see http://advertisers.mrs.org 